Journal of Animal and Veterinary Advances $10(4): 524-527,2011$

ISSN: $1680-5593$

(C) Medwell Journals, 2011

\title{
Isolating, Mapping and Spatio-Temporal Distribution Analysis of Five Ubiquitin-Specific Protease Genes in Porcine
}

\author{
${ }^{1,2}$ X. Wu, ${ }^{3}$ X.B. Zhang, ${ }^{1,2}$ L.L. Zhu, ${ }^{1}$ Y.S. Tan and ${ }^{1,2}$ X.M. Tang \\ ${ }^{1}$ Biotechnology Research Institute, Shanghai Academy of Agricultural Sciences, \\ 2901 Beidi Road, 201106 Shanghai, P.R. China \\ ${ }^{2}$ Shanghai Key Laboratory of Agricultural Genetics and Breeding, Shanghai, P.R. China \\ ${ }^{3}$ School of Food Science and Technology, \\ Huazhong Agricultural University, 430070 Wuhan, P.R. China
}

\begin{abstract}
The Ubiquitin-proteasome system is an essential mechanism for protein degradation in eukaryotes and ubiquitin-specific proteases are key effectors of the Ubiquitin-proteasome system. About 5 porcine USP genes $(14,16,38,44$ and 54) were isolated and shared high sequence similarity with their human homologues genes. Then, the tissue expression pattern of 5 porcine USP genes were analysed by RT-PCR in 2 breeds (a domestic breed and a foreign breed) and the results showed that USP 14, 16, 38 and 54 gene expression were higher in muscle tissue. In addition, researchers mapped the 5 porcine genes and all chromosomes assignments were consistent with known chromosomal homologies between human and pig. All results provided a basis for further function study of these 5 USP genes.
\end{abstract}

Key words: Ubiquitin-specific protease, porcine, mapping, expreesion, big muscle tissue, China

\section{INTRODUCTION}

Ubiquitin (Ub) is a small highly conserved protein among eukaryotes and is composed of 76 amino acids. The Ubiquitin-proteasome system is an essential mechanism for protein degradation in eukaryotes and the ubiquitin-proteasome pathway has emerged as a central player in the regulation of several diverse cellular processes (Jayhyuk et al., 2001). Recently, the Ubiquitinproteasome system is believed to play a major role in muscle wasting, degrading actin and myosin heavy chain (Ventadour and Attaix, 2006). Multiple steps were involved in the ubiquitin-proteasome pathway including ubiquitination, deubiquitination, proteasome activities. Protein ubiquitination is composed of a series of enzymatic reactions (Song et al., 2004; Zhang et al., 2003). The gene of ubiquitin-specific protease family encodes an ubiquitin-specific protease, a de-ubiquitinating enzyme which removes ubiquitin from specific protein substrates and allows protein salvage from proteasome degradation, regulation of protein localization or activation (Hershko and Ciechanover, 1998).

Ubiquitin-specific proteases are key effectors of the ubiquitin-proteasome system and are believed to degrade the major contractile skeletal muscle proteins in muscle wasting (Attaix et al., 2005). Due to USPs protease activity and their involvement in several pathologies, USPs are emerging as important target sites in the ubiquitin regulatory machinery (Daviet and Colland, 2008). The human USP gene family includes 54 genes however, USP-related research in swine has not yet reported. USP genes are important protein in muscle metabolism and muscle development is a focal research of pig breeding so researchers selected porcine USP genes as research object in this study.

\section{MATERIALS AND METHODS}

Isolating and sequencing: To isolate the porcine 14,16 , 38,44 and 54 genes, the specific primers were designed on pig EST data from NCBI using the mRNA sequences of human homology genes as probes (GenBank Acc. no.: NM_005151,NM_006447,NM_032557,NM_032147 and NM_152586).

The PCR was conducted in $20 \mu \mathrm{L}$ reaction volume consisting of $50 \mathrm{ng}$ of porcine cDNA, $1 \times$ PCR buffer, $0.6 \mu \mathrm{M}$ of each primer, $75 \mu \mathrm{M}$ of each dNTPs, $2.0 \mathrm{mM}$ $\mathrm{MgCl}_{2}$ and $2 \mathrm{U}$ Taq DNA polymerase.

The PCR parameters were $94^{\circ} \mathrm{C}$ for $5 \mathrm{~min}$ firstly and 30 cycles of $94^{\circ} \mathrm{C}$ for $20 \mathrm{sec}, 56 \sim 58^{\circ} \mathrm{C}$ for $20 \mathrm{sec}$ followed by a further $10 \mathrm{~min}$ extension at $72^{\circ} \mathrm{C}$. The PCR products were purified with Wizard prep PCR purification system

Corresponding Author: X.M. Tang, Biotechnology Research Institute, Shanghai Academy of Agricultural Sciences, 2901 Beidi Road, 201106 Shanghai, P.R. China 
and sequenced. The identities of the PCR products amplified from genomic DNA were confirmed by sequence analysis.

Chromosomal location: The 5 genes were mapped using a whole genome porcine Radiation Hybrid panel (IMpRH) (Yerle et al., 1998; Milan et al., 2000). The 25 ng ImpRH template was used in $10 \mu \mathrm{L}$ PCR reactions. The PCR results for the 5 genes were analyzed using the IMpRH mapping tool (Marklund et al., 1996)available through the IMpRH web server. The PCR typing of each gene was done twice in the IMpRH to make sure the right results which were shown in Table 1.

RT-PCR analysis of the 5 USP genes expression: The spatio-temporal expression patterns of 5 genes were

\begin{tabular}{|c|c|c|c|c|}
\hline Genes & Primer sequences $\left(5^{\prime}-3^{\prime}\right)$ & $\begin{array}{l}\text { Size } \\
\text { (bp) }\end{array}$ & $\begin{array}{l}\text { Annealing } \\
\text { Temp. }\left({ }^{\circ} \mathrm{C}\right)\end{array}$ & $\begin{array}{l}\text { Sequence } \\
\text { similarity with } \\
\text { human sequences } \\
\text { (Acc. no.) } \\
\end{array}$ \\
\hline \multirow[t]{2}{*}{ USP 14} & PF-AAAAGAGGGTAGAAGCAGAC & & & \\
\hline & PR-TTAGATAAGGCAAAGGATGG & 320 & 56 & $89 \%\left(\mathbb{N M} \_005151\right)$ \\
\hline \multirow[t]{2}{*}{ USP 16} & PF-CCTATGCCAAGGCAAGAA & & & \\
\hline & PR-AAACCACCACCCAAACATA & 466 & 58 & $87 \%\left(\mathbb{N M} \_006447\right)$ \\
\hline \multirow[t]{2}{*}{ USP 38} & PF-CTGCCTCCTGTTCATTTCG & & & \\
\hline & PR-CGCAGCCAAAGATTCCTATT & 945 & 57 & $88 \%\left(\mathbb{N M}{ }_{0} 032557\right)$ \\
\hline \multirow[t]{2}{*}{ USP 44} & PF-ACGACCATTCCATCCTCAAC & & & \\
\hline & PR-TTAGTATCCTCCTCCTGTGCC & 423 & 57 & $90 \%\left(\mathbb{N M} \_032147\right)$ \\
\hline \multirow[t]{2}{*}{ USP 54} & PF-CCCCAGCATCAAGCAGTCT & & & \\
\hline & PR-GTCAAATAAAGCCCTAAACAGC & 472 & 58 & $86 \%(\mathbb{N M} 152586)$ \\
\hline
\end{tabular}

investigated using Reverse Transcriptase-Polymerase Chain Reaction (RT-PCR). The samples (brain, skeletal muscle, liver and fat) collected from adults porcine (Chinese Fengjing pig and Duroc) were used to determine the tissue distribution of the 5 genes. PCR conditions were as follows: $5 \mathrm{~min}$ at $95^{\circ} \mathrm{C}$ followed by 28 cycles of $20 \mathrm{sec}$ at $94^{\circ} \mathrm{C}, 20 \mathrm{sec}$ at $56^{\circ} \mathrm{C}, 20 \mathrm{sec}$ at $72^{\circ} \mathrm{C}$ and a final extension of $8 \mathrm{~min}$ at $72^{\circ} \mathrm{C}$. $\beta$-actin was used as an internal control gene (Meadus, 2003).

\section{RESULTS AND DISCUSSION}

In order to study, the porcine USP genes, the first isolated the USP genes, separately. The 5 DNA fragment were obtained by PCR amplification and were belong to five porcine genes (USP 14, 16, 38, 44 and 54) by sequence analysis. The 320 bp DNA fragment of porcine USP 14 gene was $89 \%$ identical to the human (NM_005151), the 570 bp DNA fragment of porcine USP 16 gene was $87 \%$ identical to the human (NM_006447), the $945 \mathrm{bp}$ DNA fragment of porcine USP 38 gene was $88 \%$ identical to the human (NM_032557), the 423 bp DNA fragment of porcine USP 44 gene was $90 \%$ identical to the human (NM_032147), the 472 bp DNA fragment of porcine USP $5 \overline{4}$ gene was $86 \%$ identical to the human (NM_152586). These genes shared relatively high

Table 2: RH mapping of 5 porcine matrix metalloproteinase genes

\begin{tabular}{|c|c|c|c|c|c|c|c|}
\hline Genes & $\begin{array}{l}\text { GenBank Acc. } \\
\text { no. (porcine) }\end{array}$ & $\begin{array}{l}\text { Retention } \\
(\%)\end{array}$ & Lod score & $\begin{array}{l}\text { Closed } \\
\text { marker }\end{array}$ & Dist (cR) & Chr & $\begin{array}{l}\text { Human } \\
\text { localization* }^{*}\end{array}$ \\
\hline USP 14 & GQ 273966 & 22 & 4.44 & SSC 11E11 & 0.72 & $1 q 21-q 27$ & $18 \mathrm{p} 11.32$ \\
\hline USP 16 & GQ 273967 & 23 & 7.31 & S 0289 & 0.68 & $13 q 41-q 49$ & $21 \mathrm{q} 22.11$ \\
\hline USP 38 & GQ 273968 & 34 & 13.21 & S 0069 & 0.29 & $8 q 11-q 12$ & $4 q 31.10$ \\
\hline USP 44 & GQ 273969 & 35 & 8.68 & SW 1383 & 0.49 & $5 q 23-q 25$ & $12 q 22.00$ \\
\hline USP 54 & GQ 273970 & 22 & 7.22 & SW 1536 & 0.50 & 14 & $10 \mathrm{q} 22.20$ \\
\hline
\end{tabular}

*The locations of genes of the human map were obtained from http://www.ncbi.nlm.nih.gov/

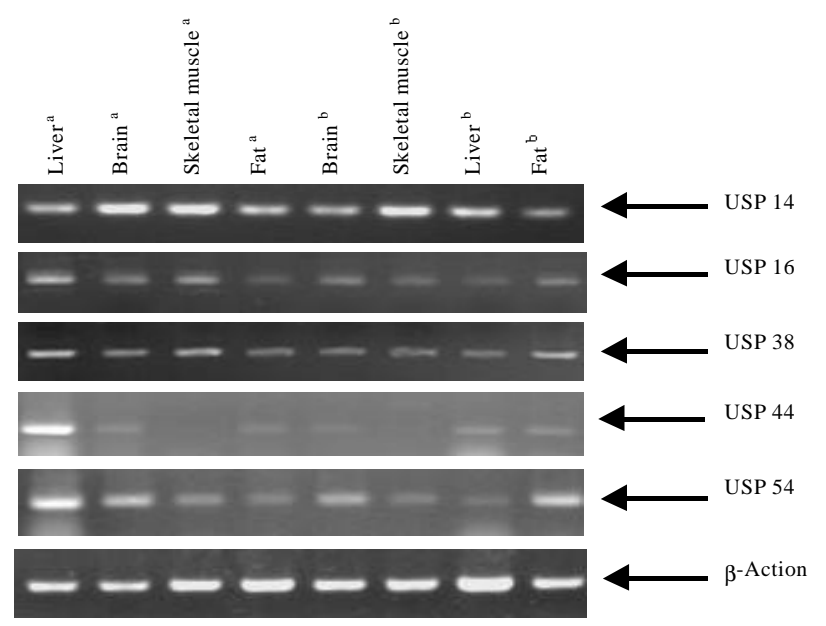

Fig. 1: The spatio-temporal expression pattern of the 5 genes; ${ }^{2}$ the tissue were collected from Fenging pig and ${ }^{b}$ the tissue were collected from Duroc 
sequence similarity with their human homologues genes, respectively so that we believed that they may have some similar functions like the human USP genes in muscle metabolism. Further, 5 genes were mapped by IMpRH panel. In Table 2 as shown understand the chromosomal location of the new genes were helpful to study the new genes functions because some chromosomal regions was the region where the known QTL or functional genes. Locations of the 5 genes were reported by choosing the closest markers.

About USP 14 was mapped on SSc1 q21-q27; USP 16 was mapped on SSc13q41-q49; USP 38 was mapped on SSc8q11-q14 and USP 44 was mapped on SSc5q23-q25. About USP 54 gene was linked with marker SW 1536 which location was inaccurate and therefore, the exact location of USP 54 was not showed in Table 1.

There are some meat quality traits QTL in 1, 5,8 and SSc 13 (Malek et a1., 2001; Zhang et a1., 2007) and USP 14, 16, 38 and 44 in these chromosomes, respectively however, these four genes whether located within these QTL regions or closely linked to their need to be further verified. In addition, investigating the genes expression in different organs and tissues was another method for an initial stage of new genes functions research. The RT-PCR results (Fig. 1) revealed that porcine USP 14, 16, 38 and 54 genes expression in brain, skeletal muscle, liver and fat of Fengjing pig and Duroc, only USP 44 gene expression was restricted to skeletal muscle.

As a whole, all the genes were detected high level of transcripts in liver of Fengjing pig and USP 14 gene expressed higher than other genes in all tissues. Fengjing pig is a well-know domestic breed for excellent meat quality originating in the Fengjing town of Jinshan district of Shanghai (Zhang et al., 2009). Duroc is a good foreign breed with fast growing. Meat quality with fast growing was the best breeding goal.

It was found that 4 genes were expressed in muscle tissue in the 2 pig breeds and the expression was higher in Fengjing than in the Duroc. The difference expressions whether associated with the meat character or growing speed in 2 breeds was a interesting question which required further related research to explanation.

\section{CONCLUSION}

There existed USP 14, 16, 38, 44 and 54 genes in porcine sharing high sequence similarity with their human homologues genes. All chromosomes assignments were consistent with known chromosomal homologies between human and pig. Tissue expression pattern showed that
USP 14, 16, 38 and 54 gene expression were higher in muscle tissue. All results provided a basis for further function study of these 5 USP genes.

\section{ACKNOWLEDGEMENTS}

The researchers would like to thank Dr. Martin Yerle for kindly providing IMpRH. This research was supported by the Natural Science Foundation of Shanghai (ZR 200914800), Qimingxing Program of Shanghai (10Q A 1406000 ) and Natural Science Foundation of China (31000789).

\section{REFERENCES}

Attaix, D., S. Ventadour, A. Codran, D. Bechet, D. Taillandier and L. Combaret, 2005. The ubiquitinproteasome system and skeletal muscle wasting. Essays Biochem. 41: 173-186.

Daviet, L. and F. Colland, 2008. Targeting ubiquitin specific proteases for drug discovery. Biochim., 90: 270-283.

Hershko, A. and A. Ciechanover, 1998. The ubiquitin system. Annu. Rev. Biochem., 67: 425-479.

Jayhyuk, M., B.K. Kyung and M.C. Craig, 2001. The ubiquitin-proteasome pathway and proteasome inhibitors. Med. Res. Rev., 21: 245-273.

Malek, M., J.C.M. Dekkers, H.K. Lee, T.J. Baas, K. Prusa, E. Huff-Lonergen and M.F. Rothschild, 2001. A molecular genome scan analysis to identify chromosomal regions influencing economic traits in the pig. II. Meat and muscle composition. Mamm. Genome, 12: 637-645

Marklund, L., M.M. Johansson, B. Hoyheim, W. Davies and M. Fredholm et al., 1996. A comprehensive linkage map of the pig based on a wild pig-Large White intercross. Anim. Genet., 27: 255-269.

Meadus, W.J., 2003. A semi-quantitative RT-PCR method to measure the in vivo effect Biol. Proced. Online, 5: $20-28$.

Milan, D., R. Hawken, C. Cabau, S. Leroux and C. Genet et al., 2000. ImpRH server: An RH mapping server available on the Web. Bioinformatics, 16: 558-559.

Song, L., S. Chen, X. Yu, Z. Wu and J. Xu, 2004. Molecular cloning and characterization of cDNA encoding a ubiquitin-conjugating enzyme from Clonorchis sinensis. Parasitol. Res., 94: 227-232.

Ventadour, S. and D. Attaix, 2006. Mechanisms of skeletal muscle atrophy. Curr. Opin. Rheumatol., 18: 631-635. 
Yerle, M., P. Pinton, A. Robic, A. Alfonso and Y. Palvadeau et al., 1998. Construction of whole genome radiation hybrid panel for high-resolution gene mapping in pigs. Cytogenet. Cell Genet., 82: 182-188.

Zhang, X.D., J.N. Jenkins, F.E. Callahan, R.G. Creech and Y. Si et al., 2003. Molecular cloning, differential expression and functional characterization of a family of class I ubiquitin-conjugating enzyme (E2) genes in cotton (Gossypium). Biochim. Biophys. Acta., 1625: 269-279.
Zhang, J., Y. Xiong, B. Zuo, M. Lei and S. Jiang et al., 2007. Mapping quantitative trait loci associated with meat quality traits in a pig population on SSC 4,8 and 13. Acta Veterinaria et Zootechnica Sinica, 38: 1009-1014.

Zhang, S.Q., G.L. Qiu, S.F. Yang, J.X. Gu, J. Zhang, Z.M. Hua and J.G. Yu, 2009. The analysis of reproductive performance of Fengjing pig groups. Shanghai J. Anim. Husbandry Vet. Med., 3: 12-13. 